\title{
Exploring the complexity of the individualistic culture through social exchange in online reviews
}

\begin{abstract}
Online reviews have reshaped visitor economies. However, there is a lack of research regarding the motivations of visitors to write online reviews as most existing research disregards the cultural differences between individuals. This research investigates the motivations of museum visitors from individualistic cultures to write online reviews with the critique of Hofstede (1980) through the lens of Social Exchange Theory (SET). This study utilises the netnography methodology. One hundred and eleven detailed TripAdvisor reviews and ten email interviews were collected. Theoretically, we contribute to SET by developing a two-dimensional framework which indicates 1) that the complexity and heterogeneity of individualist culture were identified in the dimension of social exchange between the service provider and the visitors through online reviews; and 2) American and British visitors share similar individualist culture in the second dimension of social exchange between peers in online reviews. Practically, this research can benefit the online reputation management and expectation management for visitor attractions, with the goal of improving their visitor offerings and to minimise negative reviews.
\end{abstract}

Keywords: cultural dimensions, service expectations, online reviews, British Museum, motivations, social exchange theory 


\section{Introduction}

In the past two decades, online reviews have reshaped the landscape of the visitor economy, including visitor experiences and service provider operations (Edwards et al. 2017). As a space for social exchange, online reviewing platforms allow visitors to share travel experiences and knowledge to the global population (Xiang and Gretzel 2010). Prior literature indicates the importance of culture to determine how visitors evaluate experience quality, which may impact the motivation to write online reviews (Kong and Jogaratnam 2007). The analysis of the cultural origin and its implications could lead to knowledge advancement regarding the creation of a specialised understanding of cultural origin as a powerful influencing factor, which leads to the formation of online reviews. However, most studies understand culture as a homogeneous factor without the investigations of its intra-cultural complexity.

This study aims to explore the complexity of one of Hofstede (1980)'s cultural dimensions individualist culture. Hofstede's cultural dimensions have been widely applied in understanding cross-cultural differences in consumer behaviour (see Jahandideh et al. 2014; Torres, Fu, and Lehto 2014). However, studies mostly focus on the simplicity of dualism in each dimension (i.e. collectivism vs individualism; femininity vs masculinity). Since the UK and the US have a strong individualist culture, they would be treated as a similar cultural group within this dimension with shared characteristics. However, culture is complex; it can change over time within societies - Sun, Horn, and Merritt (2004) argued that the complexity is increased due to the differences occurring at an individualist/collectivist level but also at a national level. Additionally, we explore if intra-cultural differences exist within online reviews and social interactions through the Social Exchange Theory (SET) (Wang and Liu 2019). We 
further explore how social exchanges are enhanced by online interactions (Faraj and Johnson 2010) within the intra-cultural context.

Therefore, the research focuses on investigating the complexity of the individualist culture. We aim to contribute to the critique of Hofstede's cultural dimensions by discussing the complexity and intra-cultural differences within the individualistic dimension. We use TripAdvisor as the platform to source accounts of experiences. Therefore, our research question is: What are the cultural factors of British and American visitors with reference to social exchanges and motivations to write online reviews? To achieve this, we use a netnographic approach to explore the complexity of cultural influence in expectations related to British Museum services.

The objective of the research is to explore the complexity of intra-cultural differences in online review writing through the lens of SET; therefore, the paper is structured as follows. First, a literature review of elements of cultural dimensions, service expectations, and online review behaviour will be presented. Next, we discuss the methodology, then the findings of British and American customers' experiences of service in the British Museum will be provided presented. Finally, theoretical contributions and implications will be discussed.

\section{Literature Review}

\subsection{Critique of Hofstede's Cultural Dimension Theory}

Developed from the context of corporatisation, Hofstede's $(1980,1991)$ cultural dimensions theory has been widely applied to classify and understand culture in consumer behaviours (Ladhari et al. 2011; Lee, Hwang, and Bennett 2015; Lin, Nguyen, and Lin 2013), service quality expectations (Donthu and Yoo 1998) and satisfaction (Crotts and Erdmann 2000). It categorises dominant cultures of society to systematically differentiate national cultures from each other with six dimensions: power distance, femininity/masculinity, uncertainty avoidance and individualism/collectivism, long-term orientation, and indulgence. The focus of this study 
is individualism, which is in opposition to collectivism. Individualistic societies tend to be more loosely socially connected, and individuals' self-image identified as 'I' rather than 'we'. They prioritise themselves and their immediate families.

While Hofstede's cultural dimensions provide a general understanding of how national culture expect, perceive, and evaluate service quality, it oversimplifies national culture and neglects multicultural trends as the result of globalisation as well as individual differences (Ladhari et al. 2011). Studies utilising Hofstede (1980, 1991)'s cultural dimensions so far primarily focused on cross-cultural comparisons in these dimensions, in particular, the dichotomy in each dimension; while the complexity of the culture in each dimension is overlooked. Given customers from individualistic cultures tend to have higher expectations of service quality (Donthu and Yoo 1998), and acknowledging the critiques of over-simplification of Hofstede's cultural dimension, to further understand the dimensional intra-cultural complexity, we explore British and American customers as these countries represent the highest scores of individualism (USA - 91; UK - 89) (Hofstede Insights 2020) through their service expectations and customer satisfaction.

\subsection{Service Expectations and Customer Satisfaction}

Culture plays a significant role in influencing customers' beliefs regarding service quality and satisfaction (Chen et al. 2015; Furrer, Liu, and Sudharshan 2000; Homburg, Koschate, and Hoyer 2005; Kong and Jogaratnam 2007; Li and Cai 2012). Kong and Jogaratnam (2007) suggested that service providers should seek an understanding of these cultural influences to avoid consumer dissatisfaction when culturally-specific expectations are not reached. Studies revealed that even within the same service environment, different cultural orientations of customers might have opposing service expectations and satisfaction levels (Kong and 
Jogaratnam 2007; Ladhari 2008). Two dimensions of Hofstede's theory: 'power distance' and 'individualism/collectivism' has been widely explored in service quality (Espinoza 1999; Karatepe, Yavas, and Babakus 2005). However, the complexity within the individualistic culture has been overlooked. Apart from cultural identity, Weiermair (2000) argues that tourists' expectations are also derived from both their personality traits.

There is the possibility of service dissatisfaction and failure if the cultural beliefs and norms are too dissimilar between the customer and employee (Zhang, Beatty, and Walsh 2008) due to the complexity of the interaction intensifying (Wang and Mattila 2010). Thus, the service providers must acknowledge and adapt to the specific service expectations of the customers (Zeithaml, Berry, and Parasuraman 1993). If the customer experiences dissatisfaction, the service provider may have to compensate the dissatisfied customers whom may discuss their experience in a negative manner, resulting in negative word-of-mouth (Bitner, Brown, and Meuter 2000).

The service sectors perhaps experience more of the impacts of cultural diversity - the source of consumer misinterpretations is due to conflicting cultural beliefs and norms (Bhawuk and Brislin 2000) which highlights the necessity of cultural understanding within the British Museum. Studies have also indicated that during a service encounter, customers prefer to interact with an employee/provider that possesses the same cultural beliefs and values as themselves (Sharma and $\mathrm{Wu} 2015$ ) or speaks the same language and seems culturally similar. Some customers may attach negative connotations to a different accent in a service encounter, which highlights the need for the understanding of specific cultural preferences and requirements (Rao Hill and Tombs 2011). 
Acknowledging various internal factors such as gender differences, past experiences and individual motivation affecting expectations and experiences (see Ariffin and Maghzi 2012; Zeithaml et al. 1993), the focus of the study is in the complexity of the intra-dimensional complexity and differences within the individualistic culture. We explore this through online reviewer behaviour.

\subsection{Online reviewer behaviour}

Online reviewing platforms allows tourists to share travel experiences and knowledge with ease to the global population (Xiang and Gretzel 2010), referred to as electronic word-of-mouth (eWOM). The availability of both positive and negative customer statements about a product, service or company is accessible to people online (Hennig-Thurau et al. 2004). However, with the constant technological evolution, eWOM is not solely limited to customer statements, any reposted content from customers which were initially written by other sources should also be included (Hu et al. 2014).

Tourism and eWoM literature frequently refer to SET (Cropanzano and Mitchell 2005) to comprehend the psychological behaviour associated with reviews and the motivations to exchange personal experiences (Benoit et al. 2016). SET is an appropriate theoretical lens to examine online social interactions (Wang and Liu 2019). A central component of SET is the underlying motivation of rewards - both economic and social. The key argument that SET is that information exchange rewards should surpass the costs (Benoit et al. 2016). In SET, social behaviour is the result of an exchange (Gouldner 1960) based on networks of people (Cook et al. 2006). Social exchanges can be enhanced by online interactions (Faraj and Johnson 2010), through maximising connections between network members and the relatively cheaper costs of communication (Surma 2016). A widely-agreed component of research is that reviews are 
written due to a diverse range of underlying reasons. Chen and Huang (2013) identified that reviewers rarely contribute to online reviewing platforms for economic compensation. Instead, the notion of making an impact on the world and influence purchasing behaviours of other tourists are principal motivations.

Link and $\mathrm{Xu}$ (2017) investigated the cultural factors influencing the credibility of reviews alongside the trustworthiness of the reviewer but excluded the motivational understanding about culture. Researchers have categorised the motivations that prompt the contribution to online reviewing platforms (Chen and Huang 2013). Hennig-Thurau et al. (2004) claimed the motives for eWOM contribution include: gaining societal status, seeking advice, solving problems for other consumers, venting emotions, and possessing a concern for future consumers. Although prior studies have developed a foundation of theoretical knowledge, the research has solely addressed the motivations to partake in social exchange - the consideration of differing cultural backgrounds and beliefs has not yet been aligned to motivational aspects.

Zhou (2011) concluded that the differing cultural subjective norms could influence the intention to share opinions on online reviewing platforms. Venkatesh, Morris, Davis, and Davis (2003) argued that the creation of norms could be due to peer influence - the technological acceptance amongst their community members can determine the use and access of technology. The recognition of eWOM formulating consumer attitudes and behaviours is key, especially when referring to online information exchanges (Sen and Lerman 2007). Individualist cultures depend on WOM and eWOM, which can create strong preconceptions of experiences (Laroche, Kalamas, and Cleveland 2005) and they expect the service environment to adapt according to their individual needs (Collier et al. 2018; de Mooij 2019). Although these theories have 
developed an outline of cultural and societal differentiations impacting eWOM participation, the impact of social pressure to conform to the norms may differ between cultures.

With regards to the decision-making process of selecting an attraction to visit, online reviews can be useful to portray a variety of different consumer experiences (Park, Lee, and Han 2007) and increase sales (Zhu and Zhang 2010). Park et al. (2007) argued that eWOM has two roles - to provide information and to produce recommendations for other consumers considering the discussed products or services. The importance of eWOM is higher within the attractions sector, due to the product being intangible. Purchasing intangible products poses a higher risk for the consumer because they cannot return their experiences (Reza Jalilvand and Samiei 2012). Overall, research on motives to write online reviews specifically relating to museums is scarce. Based on the literature presented above, we developed our data collection and analysis process, which is presented next.

\section{Research Methods}

A netnographic approach (Kozinets 2019) was applied in this study to gain detailed insights into British and American customers' reflections on their visiting experience. Adapted from ethnography, netnography offers an approach to seek deep understandings of online behaviour and online communications (Kozinets 2002). The nature of netnography allows the accessibility of data with a non-intrusive technique to understand consumers' personal experiences and mindset (Kulmala, Mesiranta, and Tuominen 2013; Langer and Beckman 2005). Wu and Pearce (2014) suggest netnography as an effective technique to understand perspectives of distinctive cultural groups. Compared with traditional qualitative strategies, netnography not only can help to collect naturalistic and unobtrusive data, but also is cheaper and less time-consuming (Kozinets 2002). We have followed the principles of conducting interpretive field studies by (Klein and Myers 1999; Myers 2019), and subjectivity (Hennink, 
Hutter, and Bailey 2020). In addition, the flexibility of netnography also allows the combinations of multiple research techniques to serve the purpose of answering the research question. In this study, online observations and email interviews were conducted.

\subsection{Data Collection}

TripAdvisor, the largest online eWoM platform, has been a popular eWoM site to conduct netnography (see Mkono and Tribe 2017; Thanh and Kirova 2018). There is a large number of customer reviews on the British Museum's TripAdvisor page evaluating the customer service. In this study, we apply a two-stage data collection approach. First, reviews from American and British visitors from Tripadvisor were collected. Considering the cultural approach to this study, we did not seek to exclude or include participants due to their age or gender. The reviews selected in this study have been written no longer than two years before the research, allowing for up-to-date cultural insights. All downloaded reviews then went through a rigorous screening process with 4 selection criteria (Figure 1). A variety of detailed genuine positive and negative reviews were gathered. Data collection and analysis was done chronologically starting from the most recent review then continuing in reverse time order until data saturation was reached. In total, one hundred and eleven $(\mathrm{N}=111)$ reviews were collected.

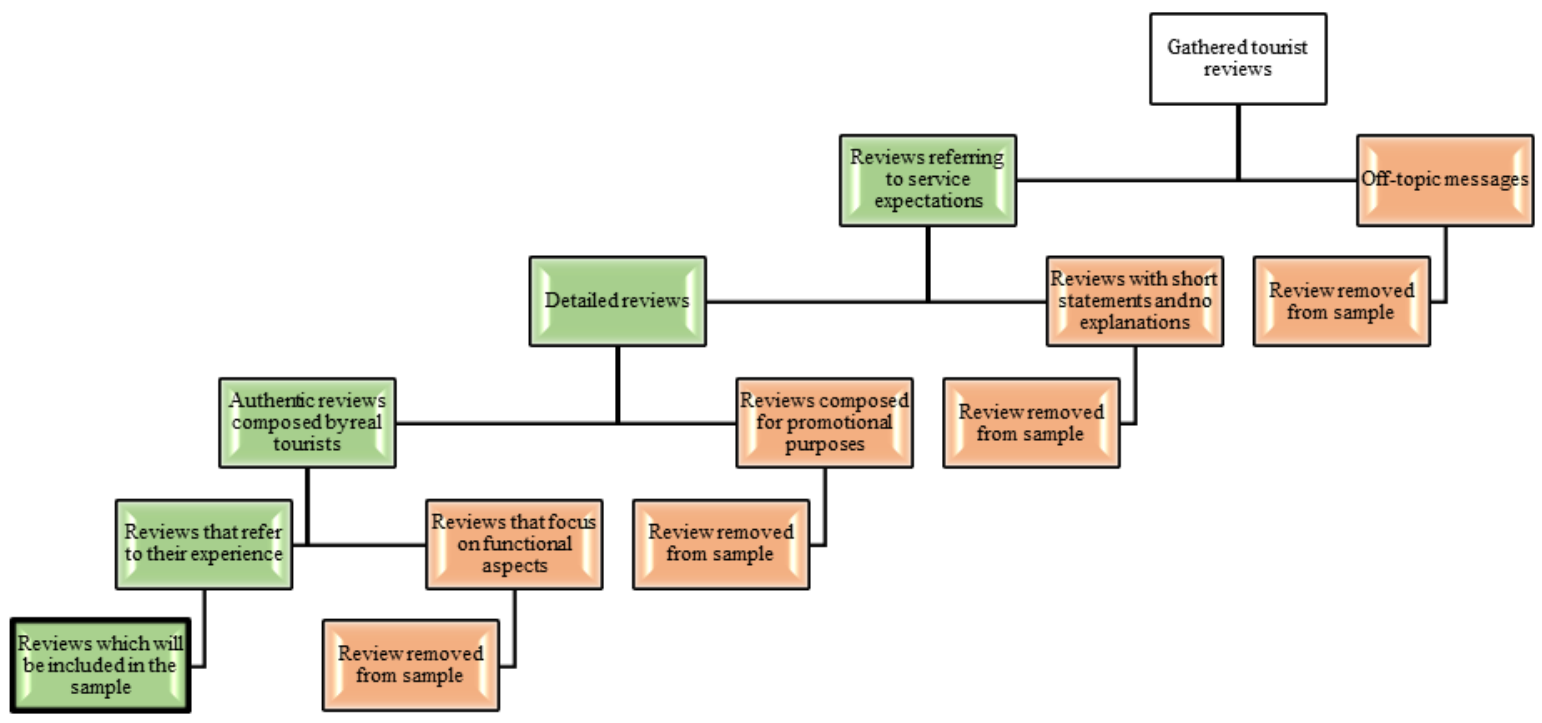

Figure 1: Criteria for reviews included in the sample 
To further explore participants' motivations, in the second stage, email interviews (Salmons 2014) were conducted from selected reviewers in stage one to explore the motivations behind online reviews further. Semi-structured email interviews were chosen to triangulate the data, to offer an opportunity for participants to thoroughly consider their responses, and reduce their apprehensions of face-to-face contacts and being audio-recorded (Gubrium et al. 2012). The email interviews contained five major questions (Appendix B). Each participant was emailed the first question and encouraged to write a detailed reply. Depending on the participant's response, related sub-questions were asked as follow up questions. This process continued until all five major questions had been answered by all participants. The participants were fully informed and consent was requested in advance. Email interviews ended when a pattern emerged and reached the state of saturation. In total, four interviews from British participants and six interviews from American participants were collected. Table 1 contains the participant information for the email interviews. Due to the nature of online research, we are unable to obtain reliable participant information from the review data. This is normal in online qualitative research (Byrne, 2017).

\begin{tabular}{|l|l|l|}
\hline Pseudonym & Cultural Origin & Sex \\
\hline Alan & Nottingham, UK & $\mathrm{M}$ \\
\hline Edward & Suffolk, UK & $\mathrm{M}$ \\
\hline William & London, UK & $\mathrm{M}$ \\
\hline Lucy & London, UK & $\mathrm{F}$ \\
\hline Alex & Texas, USA & $\mathrm{M}$ \\
\hline Kevin & New York, USA & $\mathrm{M}$ \\
\hline
\end{tabular}




\begin{tabular}{|l|l|l|} 
Jake & Ohio, USA & $\mathrm{M}$ \\
\hline Danielle & Los Angeles, USA & $\mathrm{F}$ \\
\hline Maddie & New York, USA & $\mathrm{F}$ \\
\hline Chris & Maryland, USA & $\mathrm{M}$ \\
\hline
\end{tabular}

Table 1: Email interview participants

\subsection{Data Analysis}

All the downloaded reviews and email interview transcripts were analysed through Seale (2004)'s process of thematic analysis. Two rounds of coding were conducted. In the first round, the data were coded and categorised by the first author using an open coding approach to look for motivations of review writings and the key issues of the services discussed in the online reviews. In this process, the second author checked regularly with the coding process to ensure the rigour of data analysis. An example coding table is in Appendix A. The data was then analysed through inductive reasoning by the second and third authors through the theoretical lens of social exchange theory and intra-cultural differences. First, data regarding individualist behaviour was categorised, and further investigated the intra-cultural complexity between American and British tourists, second, the lens of social exchange was applied to generate the patterns of different social exchanges directly between the British Museum and the visitors, as well as indirectly among the online communities facilitated through the virtual platform. The themes emerged were then examined and agreed by all three authors to ensure consistency and neutrality. The coders reviewed and confirmed the codes together. The analysis identified two dimensions of social exchanges through TripAdvisor, which will be presented in the next section. 


\section{Findings}

\subsection{Social exchange between the British Museum and Visitors}

The first dimension of social exchange is between the service provider and the customer facilitating by eWoM platforms such as TripAdvisor. After receiving exceptional or terrible services, some participants are motived to write reviews as a form of social return with a purpose to praise the service, damage the reputation, provide suggestions, or seek compensations. All these can be considered as social returns from the visitors to the service offered from the providers.

Edward (UK) stated that a positive review would be formed for: 'Staff doing something good that they don't have to do'. Edward described that if the British Museum staff went the extra mile, he would feel motivated to write a TripAdvisor review. Similarly, Lucy (UK) also feel motivated to praise the British Museum on TripAdvisor if the service is exceptional:

I only ever rate good experiences. If I had outstanding customer service and felt the whole experience had been faultless, I would be inclined to post on TripAdvisor' [Lucy, email interview].

Hennig-Thurau et al. (2004) noted that motivation for eWOM participation is to vent emotions. In this case, Lucy desired to vent positive emotions and to give the staff recognition for exceptional services. Differing from venting emotions on-site, as a way of social return, putting reviews on eWoM platform such as TripAdvisor is more powerful and has much larger impacts on the reputation of the business. 
Sometimes, positive reviews are written as a 'virtual thank you' for specific staff. Archie (USA) stressed the importance of staff attentiveness, the tailored service, and personal recommendations exceeded their service expectations:

'At the entrance, a staff person recommended the special exhibit "The American Dream, Pop art to present." I didn't think we'd see anything new, but we were so impressed at the selection and display of American prints that I ordered the book! I wanted to tell the staff person that she was right to recommend it, but she was gone...' [Archie, online review]

The reasons that motivating visitors to praise specific staff as a social return is down to the services provided exceed their expectations:

'If a staff member was particularly helpful or showed enthusiasm and interest I would feel motivated to write a TripAdvisor review. Also if the museum provided a good quality experience I would feel really motivated to write one'. [Jake, USA, email interview]

Jake also elaborated that the staff needed to either be helpful or to display an interest in the customer and their needs. Chris from Maryland similarly stated: 'If the knowledge and the quality of the staff reach my expectations. This would motivate me to write a review' (email interview). Therefore, for both British and American visitors, the 'extra mile' of customer service will potentially lead to a 'virtual praise' as a social return. However, the service expectations differed - motivations are personal and dependent on numerous factors with cultural background being one aspect. 
Correspondingly, many negatives were generated to complain about specific terrible customer service, especially when the service failures were not resolved in the first place. As the social return, customers leave negative reviews on TripAdvisor after the experience. Comparing with large similarities in terms of issues, British and American visitors praised the British Museum. However, the focus of complaints is somewhat different.

We found that American visitors having limited time on holiday tend to value the efficiency of the service more. Jennifer (USA) stressed discontent with the speed of service:

I finished my pot of tea and when I asked for another they forgot about it and I had to reask for it. It was 10 minutes later that I reasked. They were busy, we could see them, but.. to just bring me another pot of tea? ... I was dissapointed because I didn't want to continue to eat $w /$ out a drink, so my hot scones got cold'. [Jennifer, online review]

By providing detailed reviews, Jennifer reproduced the scenario of the service failure, which can be a damaging social return for the British Museum's reputation but could also be useful advice to improve the operations.

Contrastingly, the British customers did not mention the portion size nor the speed of service. The British visitors already had knowledge and preconceptions from experiences in Britain regarding typical food portions and speed of service in a busy environment - if dissimilarity did occur between preconceptions and experience, it was not noteworthy enough for the British visitors to include in their TripAdvisor reviews.

When the service failed, Alex (USA) tried to seek recovery first: 
'if I had cultural experience with a staff member and they were exceptionally rude I would complain first and if I wasn't satisfied with the response I would leave a bad review'. [Alex, email interview]

These findings demonstrated that Alex behaved more directly and aimed to resolve service failures before writing a TripAdvisor review. Hartman et al. (2013) concluded that visitors are more forgiving of service failures abroad - cultural differences cushion the impact of the failure. Alex implied a sense of understanding and the willingness to forgive service failures if the complaint was successfully resolved. However, this forgiving nature is not present in every visitor: 'If I really have had a bad experience in any place that I visit, TripAdvisor is a really goodbwebsite (good website) to criticise as business do look at it' [Danielle, USA, email interview]. Danielle expressed that recognition from the business regarding the service failure constitutes as a motivation to write a British Museum review. The lack of cultural homogeneity can partially explain the differed review formation motivations.

Cultural differences can cushion the impact of service failure (Hartman et al. 2013). Harry (UK) indicated a more empathetic side towards non-English speaking staff regarding service failures due to cultural misunderstandings:

'Naturally I'm more forgiving, they may have had to learn so much more for the role but I would also find it inspirational should they have passion for what they do. There may be a slight language barrier which I would have no problem with at all. As long as they were keen, pleasant and knowledgeable I would be more than happy'. [Harry, email interview] 
Harry demonstrated his patience with overcoming language barriers; however, staff friendliness is still expected, despite the cultural differences. The empathetic nature depended on the individual, and the findings suggested that there were also cultural differences amongst British visitors. Alan (UK) expressed that he: 'would expect the same standard of customer service from all staff because they've all been interviewed/hired through the same process' (email interview). These findings suggested that personality traits are another key influencer over service expectations (Weiermair 2000), and regional cultural norms can differ (Banks 2010). However, American visitors expected the same level of service regardless of cultural backgrounds: 'I wouldn't be more forgiving, as I like to receive high customer service, wherever I go' [Danielle, USA, email interview], indicating intra-cultural differences between individualist cultures.

Some negative reviews are not targeting specific staff; instead, the reviewers are hoping some actions to be developed in training by the British Museum to develop better customer services. Therefore, customers' observations and constructive feedbacks are valuable 'social returns' for the service providers. Some of the feedbacks are similar to complaints but providing some useful insights for management for improvements. For instance, not just complaining about the staff attentiveness, both British and American visitors provided information and issues that detailed enough to be addressed by operational management.

British visitors expected British Museum staff to remain focused, with the visitor in mind: ' $I$ was less than impressed by the, several examples, of museum attendants who stood in groups talking' [Karen, UK, online review]. American visitors expected more staff to be present in the museum and a higher level of attentiveness: 'Not one employee in site and if you did see one they were on their phone!' [Lily, USA, online review]. 
In addition, these reviews also show visitors both from the US and the UK expect from staff. The significance of staff interactions has been addressed in the literature, and cultural dissimilarities between the staff and visitor can lead to service failure (Zhang et al. 2008). The lack of interaction can cause a service failure and does not meet service expectations for both British and American visitors. The intensification was demonstrated by the anger expressed: 'It really did seem like it was an absolute imposition for the staff to tear themselves from chatting about their inane lives than was to rip £30 from our hands’ [Brian, UK, online review]. Brian had paid for a limited-edition exhibition and expected a higher level of service as a result. The influence of individualism is evident within this review - visitors from an individualist culture tend to expect the service environment to adapt to them (de Mooij 2019).

Georgia (UK) noted that the employee should have been more flexible to her needs:

'The girl at the ticket desk was rather surly and said that the offer was not valid at weekends. I pointed to her the terms and conditions that I had printed from the website showing nothing which stated that this was a weekday-only offer. She took a leaflet out and showed me it was a weekday offer. Fine... Unfortunately, it is very much a case of luck with who you end up being served by, as I'm certain that a customer-focused employee would have been friendlier and flexible' (online review).

\subsection{Social exchange between peers}

The second dimension of the social exchange is between review readers and reviewers on TripAdvisor. These reviews created preconceived notions of the British Museum and influenced the peers' service expectations, which then impacted the levels of experience satisfaction. Söderlund and Rosengren (2007) argued that psychological constructs are formed 
before an experience. EWoM today acts as a powerful tool in constructing attraction images and reputations. Due to the power of eWoM, the British Museum has a big reputation, which results in high expectations for visitors. By reading reviews, some visitors are very excited before the visit: 'truly we were ready to be wowed by this museum with its reviews' [Abigail, USA, online review]. And the excitement also comes with high expectations: 'I would expect it too be very high particularly as it is a proven visitors destination and possibily provides a impression of Britain to visitors from all over the world' [Edward, UK, email interview]. Joe expected a higher level of service due to the reputation of the British Museum as one of London's top visitor attractions: 'I expect a higher standard of service from one of London's premier attractions' [Joe, UK, email interview].

However, British visitors and American visitors have different interpretations of this abstract reputation. British customers tend to value more if the customer service as a significant element constructing the experience match with the high reputation of the British Museum: 'staff should be approachable and willing to help and answer any questions' [Alan, UK, email interview].

Sophie (UK) stressed that the British Museum possessed: 'Some of the best and most interesting material to see anywhere in the world but that does not excuse poor customer service' (online review). Also, Edward expressed that the reputation of the British Museum should correlate to a higher level of service, in comparison to less-established visitor attractions. Reputation can partially be established online via WOM and eWOM, which then forms consumer attitudes (Sen and Lerman 2007) and forms psychological constructs prior to the experience. 
In comparison, the American visitors included in this study interpreted the big reputation as the quality the exhibits, and they can be rather critical in the evaluation: '...overall I don't think that they have interesting things to see. Especially when it's a museum that's so big and popular' [Camila, USA, online review]. Fred (USA) highlighted that: 'Perhaps because they have unparalleled artifacts, they don't need to be as creative. They should be' (online review), concluding that the British Museum should not rely on its reputation to guarantee experience satisfaction - British visitors included in the sample value customer service and creative exhibitions is vital to meet the expectations of American visitors.

Participants agreed reading reviews about the British Museum and noted down the dos and don'ts shared by other peers before the visit. As a social return, many would share with their experiences back to TripAdvisor, and hoping this might be helpful for fellow users. For American visitors, they tend to compare with services and food back home. This first-hand experience and comparison could potentially help other peers reading the reviews better prepared for their trip. Jennifer (USA) explained: 'The desserts were good and the sandwiches were not. very bland. I don't know if all British tea sandwiches are like that because I have only had Tea in America' (online review). The quality of food was directly compared to American food quality, the dissimilarity between the preconceptions of the British Museum and the experience resulted in a service failure.

As international visitors, American visitors had preconceived service expectations before the visit by reading online reviews and compared their experiences to those in America: 'maybe im from New York and not used to their pace' (Veronica, USA, online review). It is important to note that there are intra-cultural differentiations regarding the pace of life and the resulting 
service expectations. The cultural norms differentiating service expectations, and resulting in review writings is supported by Zhou (2011).

These reviews identified that American visitors included in the sample ranked speed of service as a key indicator of experience satisfaction. American visitors, on the one hand, construct their service expectations through reviews, on the other, reflecting the experience through comparing the differences between two countries' service styles, and aimed to offer tips and honest opinions for fellow visitors as social return hoping them to have positive experiences: 'So do not book the 90 minute highlight tour offered by the museum. Although this is very subjective, if you only have time for one museum on your stay, make it the National Gallery. The art is more impressive that the artifacts that get lost in the volume of not so impressive stuff'. [Matthew, USA, online review]

Hennig-Thurau et al. (2004) argued that possessing a concern for future visitors is a key motivator to write reviews. But different from British customers having more opportunities to revisit the museum, for American visitors like Matthew, they would like to maximise the opportunity in the visit during their limited time in London.

Although having more opportunities to revisit the museum, we found that British participants tend to value more of using reviews to influence others and ensure them to have a good experience (Walsh, Gwinner, and Swanson 2004): 'I would write a review if I would think my experience could influence another person's choice as to whether they should visit or not' [Alan, UK, email interview]. The British visitors do not only seek to influence purchasing decisions - if they have a pleasant experience, but they also aim 'to ensure other people had 
the same experience' [Lucy, UK, email interview]. They want to positively impact the visitors and provide recommendations based on their own experiences.

The positive image of the British Museum that collectively constructed by reviewers would make some visitors reflect if their negative experience is only an exception, and still recommend the site to others as 'social return'. After a negative experience, Camila (USA) still recommended other prospective visitors to visit: 'still encourage you a little bit to come just to see if you like it since the reviews are so high...maybe we just visited at the wrong time' (online review) demonstrating the power of TripAdvisor reviews. Despite a service failure, the high rating led Camila to believe that her negative experience was an isolated example. Laroche et al. (2005) have highlighted customers from individualist cultures heavily base their preconceptions on eWOM. Some even suppressing or doubting their own experience and confirm the collective attraction image of the site.

Not only posting their own experiences, but some participants were also echoing specific reviews they previously read and validate them as a 'social return'. After a service failure, Chloe (UK) searched for reviews by other visitors that also had their British Museum service expectations not met:

'We visited on Saturday 17th March and I would echo what other reviewers who have given a "terrible" review have said. Our experience was made worse by the intransigence of customer service on the day who were unsymapthetic and didn't even offer a refund. After looking at Trip Advisor later I saw that many people did get a refund so I emailed the Museum later and have had a no-questions asked refund' (online review). 
Although Chloe emailed the British Museum to get a refund and expected economic compensation for the service failure, the motivation to write an online review was not for economic purposes - TripAdvisor was utilised to research whether a refund was possible and to validate previous reviews.

\section{Discussion}

This study was motivated because many previous studies which have utilised Hofstede (1980, 1991)'s cultural dimensions to make cultural comparisons, while the complexity within each of the cultural dimensions is often overlooked. A further criticism of Hofstede's dimensions is that they oversimplify national cultural while neglecting multicultural trends and individual differences (Ladhari et al. 2011). Therefore, we explored the intra-cultural differences within the individualistic cultures by comparing British and American visitors online reviews, and linked these cultural dimensions with service expectations. Chang, $\mathrm{Ku}$ and Chen (2019) based their analysis of online reviews on business environments, whilst this study is focussed on the service quality and satisfaction in the visitor economy. Previous research has found that culture does play a significant role in influencing the believes that customers have regarding service quality and satisfaction (Chen et al. 2015; Furrer, Liu, and Sudharshan 2000; Homburg, Koschate, and Hoyer 2005; Kong and Jogaratnam 2007; Li and Cai 2012). However, much of the previous research has explored these differences between cultures. In this study, we demonstrated that there are also differences within the individualistic cultures. Other studies have also shown that within the same service environment (e.g. a museum), that the different cultural orientations of visitors have an impact on service expectations and satisfaction levels (Kong and Jogaratnam 2007; Ladhari 2008). We found that this was also true in intra-cultural groups. Previous research has demonstrated that these differences occur between cultural 
groups (Espinoza 1999; Karatepe, Yavas, and Babakus 2005), and we have further demonstrated that they also occur within a cultural dimension as there were often differences between the service expectations of British and American visitors.

Online reviews have been shown to provide value (Neirottia, Raguseob and Paolucci 2016). However, little is known about the intra-cultural aspects of online reviews. Previous research has also shown that there is a possibility of service dissatisfaction if the cultural beliefs and norms between the service provider and visitor are too dissimilar (Zhang, Beatty, and Walsh 2008) and that during a service encounter, customers prefer to interact with an employee from the same cultural group as themselves (Sharma and $\mathrm{Wu}$ 2015). We found that this was particularly true for British visitors as they expected English to be spoken well and that friendliness was always expected at all times, while American visitors were less concerned. This has further emphasised that some customers may attach negative connotations to different accents during a service encounter (Rao Hill and Tombs 2011). Although service providers must acknowledge and adapt to the service expectations of their customers (Zeithaml, Berry, and Parasuraman 1993), we found this to be more important for American visitors. Americans tend to value the efficiency of the service, and can provide potentially damaging social returns through online reviews if they are not satisfied if a complaint was handled well. This reinforces the idea of service providers ensuring that customer satisfaction is maintained based on online reviews (Antioco and Coussement 2018) and that value is maintained (Neirottia et al. 2016).

Individualistic cultures such as British and Americans tend to have high expectations of service quality (Donthu and Yoo 1998). However, we found that this was not always the case. British visitors had higher expectations of service experiences because of the reputation of the museum; while American visitors were less interested in customer service expectations and 
based their expectations on the quality of the exhibits. Previous research has argued that people expect service environments to adapt according to their individual needs (Collier et al. 2018; de Mooij 2019), and in more recent times to adapt from online reviews (Xu, Wang, Li, and Haghighi 2017). Although this was mostly true only for British visitors, American visitors were focussed on the reliance of the online reputation (Sen and Lerman 2007) of the attraction to guarantee satisfaction. American visitors were also less interested in customer service. Reputation also played a role in expectations and was demonstrated by the way in which British and American visitors used existing reviews. For the British visitors, the excitement they got from reading reviews also lead to much higher expectations of the service experience, while the American visitors expected a high level of service due to the reputation of the museum. This is perhaps because of the different social mechanisms underpinning review writing or evaluation (Davis and Agrawal 2018).

Because online reviews contain user-generated data which can be useful for organisations (Chang et al. 2019), we explored the motivations for writing reviews between British and American visitors with a focus on the different cultural subjective norms, which could influence the intention to share opinions on online reviewing platforms (Zhou, 2011). Previous research on social exchanges through online reviews identified that reviewers rarely contribute to online reviewing platforms for economic compensation and were more interested in making an impact on the world and influencing others (Chen and Huang 2013). Although we found this to be true, the underlying reasons for writing reviews were different across the British and American visitors. British visitors tended to be more interested in writing reviews to influence others to ensure they had a good experience based on their own experiences. American visitors tended to be more focused on helping other American visitors by comparing things with how they are back home. However, review writing about negative experiences was similar between 
the British and Americans. Both groups considered negative experiences to be isolated events, and would still write reviews to recommend the museum, or to compare their own negative experiences against other visitors positive experiences. This demonstrates that there is some commonality within the cultural dimension, in particular with the way in which people suppress negative feelings to maintain the overall good image of the attraction (Laroche et al. 2005). Our findings reinforce the motivations for eWoM contribution (Hennig-Thurau et al. 2004) and have further taken into consideration the different cultural backgrounds of review writing which had previously not been aligned to motivational aspects.

\subsection{Theoretical Contribution and Implications}

Theoretically, this article contributes to a two-dimensional framework of SET to understand motivations of writing online reviews (figure 2). In addition, the complexity of individualistic culture has different interpretations in each dimension. In the first dimension, social exchanges between the service provider and the customer are facilitated by eWoM platforms. This type of social exchange is more direct, and many are about specific cases or experience. Intracultural differences between American and British visitors within individualist cultures, regional cultural norms (Banks 2010) and different personality traits (Weiermair 2000) were identified in the findings. This dimension illustrates the complexity and heterogeneity of individualist culture by comparing American and British visitors' service expectations and experiences through online social exchange between the visitor and the provider. Firstly, Americans tend to associate their high expectations with high quality of exhibits, whilst British visitors value more on the service element. Secondly, compared with their British counterparts, American visitors value more on the service speed due to the limited time on holiday. Thirdly, service failure occurs more on American visitors due to different service style and portion size between two countries; however, American visitors also tend to be more forgiving, which can be explained through the culture cushion theory (Hartman et al. 2013). 


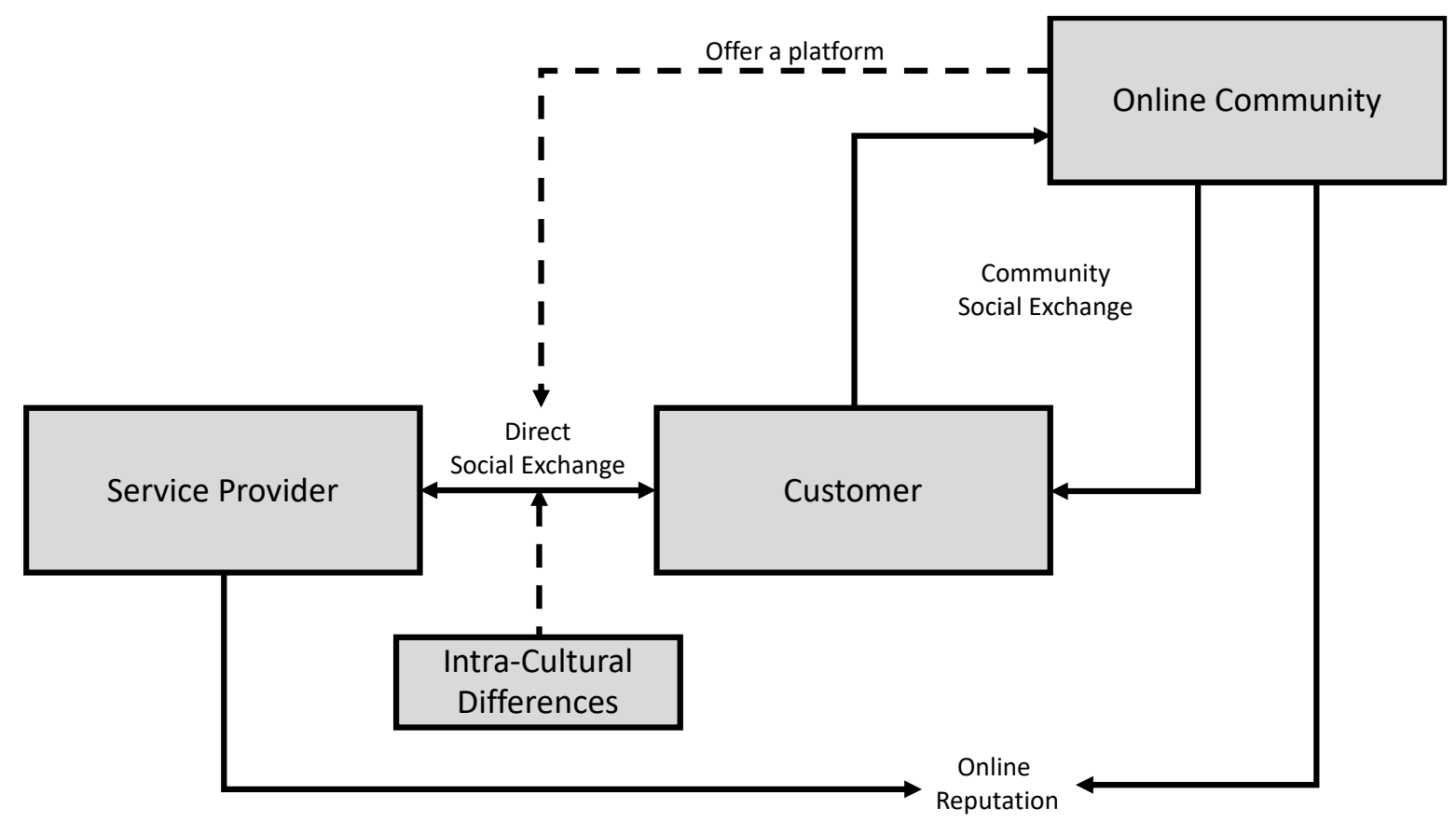

Figure 2: SET contribution

The second dimension is the social exchange within the community. Customers read and give feedback on eWoM platforms. Apart from some minor cases which echo other reviews, most reviews are not written for a specific reader, but rather towards the broader community. In this dimension, American and British travellers sharing similarities in terms of highly influenced by eWoM and sharing personal opinions through reviews to ensure others also have great experiences (Laroche et al. 2005). Compared with social exchanges in social media (Surma 2016), we discovered that there is a lower expectation that the reviewer will receive a reciprocal reward (Gefen and Ridings 2002) for writing the review. This is because social exchanges differ to economic exchange (Blau 1964), and in the case of writing reviews it is more likely that a reviewer will never know the true impact of their review due to limited social interactions and a focus on opinions and experiences (Hennig-Thurau et al. 2004). Social exchanges also come about due to altruism as consumers share their experiences with others as an expression to help others in decision making (Munzel and Kunz 2014), and a willingness to share within virtual communities (Jinyang 2015). Some reviews reinforce the attraction image and 
reputation, whilst some challenge it. Overall these reviews develop a dynamic process of shaping the attractions' image and visitors' perceptions, demonstrating the social rewards (Gefen and Ridings 2002) received from the information exchange (Benoit et al. 2016) when writing reviews can have a broad impact on a service provider.

Our findings also demonstrate social exchanges differ between individualist cultures - they expect the service environment to adapt to them (Laroche et al. 2005), one could conclude that the service expectations occasionally differed between cultures but also between individuals. This is reinforced because sharing within the same culture can facilitate engagement and help decision making (Afonso Dias, Correia, and José Martínez López 2014). Social exchanges existed in our study not only between the visitor and the museum staff, but also between the visitor (writing a review), and the reader of the review. While the former is a physical social exchange, the latter is a social exchange facilitated by technology with relatively low costs compared with other forms of knowledge exchange (Surma 2016).

\subsection{Implications for Practice}

Three implications for practice were identified for stakeholders. First, when trying to understand a group of people from individualist culture, it is important to understand the cultural differences that may exist within that group. This implication is also transferable for other service providers that develop their consumer profile using Hofstede's cultural dimensions. When developing consumer profile, the provider should not over-rely on the simplicity of the cultural dimensions; instead, more engagement of understanding intra-cultural complexities and the intersectionality between cultural backgrounds with other dimensions should also be taken into account. 
Second, the research confirmed that the level of museum staff attentiveness correlates to a large proportion of experience satisfaction. Two dimensions of social exchange through eWoM provided a practical framework of online reputation management and service improvement for visitor attractions. Service providers should pay attention to both dimensions concurrently to improve service quality and reputation. This requires not only data specialist to monitor and analyse online review regularly in the community social exchange, but also customer service managers proactively respond individually with customised messages to resolve customers' problems through direct social exchange. Cultural factors should be considered in these communications to avoid misunderstandings. These results online review analysis needs to reflect on the improvement and updates of marketing strategies and operational plan.

Third, the existing literature explicitly relating to the British Museum is scarce and outdated; this study has addressed the literature gap. The findings can also be transferred to other service environments - the British Museum provides a diverse service offering, with the presence of cafés, gift shops and exhibitions. The motivations to write TripAdvisor reviews discussed in this study could be applied to other visitor attractions. By understanding what motivates visitors to write online reviews as well as what customers are commonly complaining through online reviews, service providers can focus on areas such as expectation management, matching the service quality of the 'supporting elements' (e.g. café, souvenir shop) with the key content of the attraction, and standardise of the service speed.

\subsection{Limitations and Future Research Directions}

This study has some limitations. There is a risk that ingenuine reviews could have filtered into the sampling population, i.e. fake or biased reviews that can be created by individuals that want to shed perceptions on the British Museum. There can be issues when using social media in 
research; language can be interpreted in different manners (McKenna, Myers, and Newman 2017). Despite reviews being available online (Rageh and Melewar 2013), accessibility was still an issue - some participants did not respond, and a few profiles were inactive, which meant the researcher could use those reviewers in the sample. In addition, the field site in this study is limited to TripAdvisor. Although the rationale of choosing Tripadvisor only is to help researchers to immerse in the site, we acknowledge there are other popular review sites such as Yelp which are popular for US users.

Future research can expand, test and apply this two-dimensional framework of SET in different contexts through both qualitative and quantitative approaches. In addition, we encourage future research on eWoM to go beyond applied research, and engage more with theoretical development, and critically evaluate and re-examine its potential impacts on wellbeing and societies. Future research can consider adopting an overt approach, which would allow greater depth of data collection, including age, gender, social backgrounds, and cultural origins of the participants allowing the researcher to gain further clarification from participants about the true meaning of their responses. An overt approach could further investigate the impact of personality traits and their influence on British Museum service expectations and review motivations. An alternative approach would be to carry out data collection in a quantitative manner - which could provide stronger correlations within the data due to the more massive data sets.

\section{Conclusion}

The complexity within Hofstede (1980, 1991)'s cultural dimensions is often overlooked. Therefore, in this study, we used online reviews to investigate the complexity of individualist cultures. Exploring the intracultural differences between British and American individualist cultures, we uncovered some differences in their use and motivations to contribute to online 
reviews. Developing SET in the context of eWoM, we proposed a two-dimensional framework for social exchange in online reviews, which considers the relationship between customers, online communities, and service providers. Service providers should be mindful for both dimensions concurrently to maintain a sustainable online reputation to improve customer satisfaction. In addition, service providers should not over-rely on the simplicity of cultural dimensions and pay attention to cultural differences to improve service quality and reputation.

\section{References}

Afonso Dias, Joana, Antónia Correia, and Francisco José Martínez López. 2014. 'From Information-Sharing to Vacation Rental Choices - the Case of Albufeira, Portugal'. International Journal of Culture, Tourism and Hospitality Research 8(1):35-47.

Antioco, M., \& Coussement, K. (2018). Misreading of consumer dissatisfaction in online product reviews: Writing style as a cause for bias. International Journal of Information Management, 38(1), 301-310.

Ariffin, Ahmad Azmi M., and Atefeh Maghzi. 2012. 'A Preliminary Study on Customer Expectations of Hotel Hospitality: Influences of Personal and Hotel Factors'. International Journal of Hospitality Management 31(1):191-98.

Banks, J. 2010. 'Multicultural Education: Characteristics and Goals'. Pp. 3-26 in Multicultural Education-Issues and Perspectives, edited by J. A. Banks and C. A. McGee. Hoboken: John Wiley \& Sons.

Benoit, Sabine, Nicola Bilstein, Jens Hogreve, and Christina Sichtmann. 2016. 'Explaining Social Exchanges in Information-Based Online Communities (IBOCs)'. Journal of Service Management 27(4):460-80. 
Bhawuk, Dharm, and Richard Brislin. 2000. 'Cross-Cultural Training: A Review'. Applied Psychology 49(1):162-91.

Bitner, Mary Jo, Stephen W. Brown, and Matthew L. Meuter. 2000. 'Technology Infusion in Service Encounters'. Journal of the Academy of Marketing Science 28(1):138-49.

Blau, Peter. 1964. Power and Exchange in Social Life. New York: J Wiley \& Sons.

Byrne, C. (2017). Anonymous Social Media and Qualitative Inquiry: Methodological Considerations and Implications for Using Yik Yak as a Qualitative Data Source. Qualitative Inquiry, 23(10), 799-807.

Chang, Y.-C., Ku, C.-H., \& Chen, C.-H. (2019). Social media analytics: Extracting and visualizing Hilton hotel ratings and reviews from TripAdvisor. International Journal of Information Management, 48, 263-279.

Chen, Beiwen, Maarten Vansteenkiste, Wim Beyers, Liesbet Boone, Edward L. Deci, Jolene Van der Kaap-Deeder, Bart Duriez, Willy Lens, Lennia Matos, Athanasios Mouratidis, Richard M. Ryan, Kennon M. Sheldon, Bart Soenens, Stijn Van Petegem, and Joke Verstuyf. 2015. 'Basic Psychological Need Satisfaction, Need Frustration, and Need Strength across Four Cultures'. Motivation and Emotion 39(2):216-36.

Chen, Hua-Ning, and Chun-Yao Huang. 2013. 'An Investigation into Online Reviewers' Behavior'. European Journal of Marketing 47(10):1758-73.

Collier, Joel E., Donald C. Barnes, Alexandra K. Abney, and Mark J. Pelletier. 2018. 'Idiosyncratic Service Experiences: When Customers Desire the Extraordinary in a Service Encounter'. Journal of Business Research 84:150-61. 
Cook, Karen S., C. Cheshire, E. R. Rice, and S. Nakagawa. 2006. Social Exchange Theory. Handbook of Sociology and Social Research. Springer.

Cropanzano, Russell, and Marie S. Mitchell. 2005. 'Social Exchange Theory: An Interdisciplinary Review'. Journal of Management 31(6):874-900.

Crotts, John C., and Ron Erdmann. 2000. 'Does National Culture Influence Consumers' Evaluation of Travel Services? A Test of Hofstede's Model of Cross-cultural Differences'. Managing Service Quality: An International Journal 10(6):410-19.

Davis, J. M., \& Agrawal, D. (2018). Understanding the role of interpersonal identification in online review evaluation: An information processing perspective. International Journal of Information Management, 38(1), 140-149.

Donthu, Naveen, and Boonghee Yoo. 1998. 'Cultural Influences on Service Quality Expectations'. Journal of Service Research 1(2):178-86.

Edwards, Deborah, Mingming Cheng, IpKin Anthony Wong, Jian Zhang, and Qiang Wu. 2017. 'Ambassadors of Knowledge Sharing: Co-Produced Travel Information through Tourist-Local Social Media Exchange'. International Journal of Contemporary Hospitality Management 29(2):690-708.

Espinoza, Miguel Morales. 1999. 'Assessing the Cross-Cultural Applicability of a Service Quality Measure A Comparative Study between Quebec and Peru'. International Journal of Service Industry Management.

Faraj, Samer, and Steven L. Johnson. 2010. 'Network Exchange Patterns in Online Communities'. Organization Science 22(6):1464-80. 
Furrer, Olivier, Ben Shaw-Ching Liu, and D. Sudharshan. 2000. 'The Relationships between Culture and Service Quality Perceptions:Basis for Cross-Cultural Market Segmentation and Resource Allocation'. Journal of Service Research 2(4):355-71.

Gefen, David, and Catherine M. Ridings. 2002. 'Implementation Team Responsiveness and User Evaluation of Customer Relationship Management: A Quasi-Experimental Design Study of Social Exchange Theory'. Journal of Management Information Systems 19(1):47-69.

Gouldner, Alvin W. 1960. 'The Norm of Reciprocity: A Preliminary Statement'. American Sociological Review 25(2):161-78.

Gubrium, Jaber F., James A. Holstein, Amir B. Marvasti, and Karyn D. McKinney. 2012. The SAGE Handbook of Interview Research: The Complexity of the Craft. Sage Publications.

Hartman, Katherine, Tracy Meyer, and Heather Hurley. 2013. 'An Examination of Culture Cushion: Antecedents and Consequences'. International Journal of Culture, Tourism and Hospitality Research 7(4):340-52.

Heidenreich, Martin, and Beatriz Plaza. 2015. 'Renewal through Culture? The Role of Museums in the Renewal of Industrial Regions in Europe'. European Planning Studies 23(8):1441-55.

Hennig-Thurau, Thorsten, Kevin P. Gwinner, Gianfranco Walsh, and Dwayne D. Gremler. 2004. 'Electronic Word-of-Mouth via Consumer-Opinion Platforms: What Motivates Consumers to Articulate Themselves on the Internet?' Journal of Interactive Marketing 18(1):38-52. 
Hennink, Monique, Inge Hutter, and Ajay Bailey. 2020. Qualitative Research Methods. London: SAGE.

Hofstede, G. 1980. Culture's Consequences: International Differences in Work-Related Values. Beverly Hills: SAGE Publications Ltd.

Hofstede, G. 1991. Culture and Organisations: International Cooperation and Its Importance for Survival. London: Harper Collins.

Hofstede Insights. 2020. 'Country Comparison'. Hofstede Insights. Retrieved 31 March 2020 (https://www.hofstede-insights.com/country-comparison/).

Homburg, Christian, Nicole Koschate, and Wayne D. Hoyer. 2005. 'Do Satisfied Customers Really Pay More? A Study of the Relationship between Customer Satisfaction and Willingness to Pay'. Journal of Marketing 69(2):84-96.

Hu, X., L. Ha, S. Mo, and Y. Xu. 2014. 'Who Are Fans of Facebook Fan Pages? An Electronic Word-of-Mouth Communication Perspective'. International Journal of Cyber Society and Education 7(2):125-46.

Jahandideh, Behrouz, Alireza Golmohammadi, Fang Meng, Kevin D. O`Gorman, and Babak Taheri. 2014. 'Cross-Cultural Comparison of Chinese and Arab Consumer Complaint Behavior in the Hotel Context'. International Journal of Hospitality Management 41:67-76.

Jinyang, Li. 2015. 'Knowledge Sharing in Virtual Communities: A Social Exchange Theory Perspective'. Journal of Industrial Engineering and Management 8(1):170-83. 
Karatepe, Osman M., Ugur Yavas, and Emin Babakus. 2005. 'Measuring Service Quality of Banks: Scale Development and Validation'. Journal of Retailing and Consumer Services 12(5):373-383.

Klein, Heinz K., and Michael D. Myers. 1999. 'A Set of Principles for Conducting and Evaluating Interpretive Field Studies in Information Systems'. MIS Quarterly 23(1):67-93.

Kong, Mikyoung, and Giri Jogaratnam. 2007. 'The Influence of Culture on Perceptions of Service Employee Behavior'. Managing Service Quality: An International Journal 17(3):275-97.

Kozinets, Robert V. 2002. 'The Field behind the Screen: Using Netnography for Marketing Research in Online Communities'. Journal of Marketing Research 39(1):61-72.

Kozinets, Robert V. 2019. Netnography: The Essential Guide to Qualitative Social Media Research. London: SAGE.

Kulmala, Marianne, Nina Mesiranta, and Pekka Tuominen. 2013. 'Organic and Amplified EWOM in Consumer Fashion Blogs'. Journal of Fashion Marketing and Management: An International Journal 17(1):20-37.

Ladhari, Riadh. 2008. 'Alternative Measures of Service Quality: A Review'. Managing Service Quality: An International Journal 18(1):65-86.

Ladhari, Riadh, Frank Pons, Grégory Bressolles, and Michel Zins. 2011. 'Culture and Personal Values: How They Influence Perceived Service Quality'. Journal of Business Research 64(9):951-57. 
Langer, Roy, and Suzanne C. Beckman. 2005. 'Sensitive Research Topics: Netnography Revisited'. Qualitative Market Research: An International Journal 8(2):189-203.

Laroche, Michel, Maria Kalamas, and Mark Cleveland. 2005. "I" versus "We": How Individualists and Collectivists Use Information Sources to Formulate Their Service Expectations'. International Marketing Review 22(3):279-308.

Lee, Hye Eun, Joyce Hyunjoo Hwang, and Keri Bennett. 2015. 'Understanding Culture on the Effectiveness of Restaurant Servers' Check-Back Style'. International Journal of Contemporary Hospitality Management 27(8):1905-26.

Li, Mimi, and Liping A. Cai. 2012. 'The Effects of Personal Values on Travel Motivation and Behavioral Intention'. Journal of Travel Research 51(4):473-87.

Lin, Carolyn A., and Xiaowen Xu. 2017. 'Effectiveness of Online Consumer Reviews: The Influence of Valence, Reviewer Ethnicity, Social Distance and Source Trustworthiness'. Internet Research 27(2):362-80.

Lin, Chinho, Conghoang Nguyen, and Binshan Lin. 2013. 'Impact of Cultural Differences on Foreign Customers' Perceived Local Services'. Journal of Services Marketing 27(6):500-510.

McKenna, Brad, Michael D. Myers, and Michael Newman. 2017. 'Social Media in Qualitative Research: Challenges and Recommendations'. Information and Organization 27(2):87-99.

Mkono, Muchazondida, and John Tribe. 2017. 'Beyond Reviewing: Uncovering the Multiple Roles of Tourism Social Media Users'. Journal of Travel Research 56(3):287-98. 
de Mooij, Marieke. 2019. Consumer Behavior and Culture: Consequences for Global Marketing and Advertising. SAGE.

Munzel, Andreas, and Werner H. Kunz. 2014. 'Creators, Multipliers, and Lurkers: Who Contributes and Who Benefits at Online Review Sites'. Journal of Service Management 25(1):49-74.

Myers, Michael D. 2019. Qualitative Research in Business and Management. London: SAGE.

Neirotti, P., Raguseo, E., \& Paolucci, E. (2016). Are customers' reviews creating value in the hospitality industry? Exploring the moderating effects of market positioning. International Journal of Information Management, 36(6), 1133-1143.

Park, Do-Hyung, Jumin Lee, and Ingoo \% J International journal of electronic commerce Han. 2007. 'The Effect of Online Consumer Reviews on Consumer Purchasing Intention: The Moderating Role of Involvement'. 11(4):125-48.

Rageh, Ahmed, and TC \%J Qualitative Market Research: An International Journal Melewar. 2013. 'Using Netnography Research Method to Reveal the Underlying Dimensions of the Customer/Tourist Experience'. 16(2):126-49.

Rao Hill, Sally, and Alastair \%J Managing Service Quality: An International Journal Tombs. 2011. 'The Effect of Accent of Service Employee on Customer Service Evaluation'. 21(6):649-66.

Reza Jalilvand, Mohammad, and Neda Samiei. 2012. 'The Effect of Electronic Word of Mouth on Brand Image and Purchase Intention: An Empirical Study in the Automobile Industry in Iran'. Marketing Intelligence \& Planning 30(4):460-76. 
Salmons, Janet. 2014. Qualitative Online Interviews: Strategies, Design, and Skills. London: SAGE.

Seale, Clive. 2004. Researching Society and Culture. London: Sage.

Sen, Shahana, and Dawn Lerman. 2007. 'Why Are You Telling Me This? An Examination into Negative Consumer Reviews on the Web'. Journal of Interactive Marketing 21(4):7694.

Sharma, Piyush, and Zhan Wu. 2015. 'Consumer Ethnocentrism vs. Intercultural Competence as Moderators in Intercultural Service Encounters'. Journal of Services Marketing 29(2):93-102.

Söderlund, Magnus, and Sara Rosengren. 2007. 'Receiving Word-of-Mouth from the Service Customer: An Emotion-Based Effectiveness Assessment'. Journal of Retailing and Consumer Services 14(2):123-36.

Sun, Tao, Marty Horn, and Dennis Merritt. 2004. 'Values and Lifestyles of Individualists and Collectivists: A Study on Chinese, Japanese, British and US Consumers'. 21(5):31831.

Surma, Jerzy. 2016. 'Social Exchange in Online Social Networks. The Reciprocity Phenomenon on Facebook'. Computer Communications 73:342-46.

Thanh, Tan Vo, and Valentina Kirova. 2018. 'Wine Tourism Experience: A Netnography Study’. Journal of Business Research 83:30-37.

Torres, Edwin N., Xiaoxiao Fu, and Xinran Lehto. 2014. 'Examining Key Drivers of Customer Delight in a Hotel Experience: A Cross-Cultural Perspective'. International Journal of Hospitality Management 36:255-62. 
Venkatesh, Viswanath, Michael G. Morris, Gordon B. Davis, and Fred D. Davis. 2003. 'User Acceptance of Information Technology: Toward a Unified View'. MIS Quarterly 27(3):425-78.

Walsh, Gianfranco, Kevin P. Gwinner, and Scott R. Swanson. 2004. 'What Makes Mavens Tick? Exploring the Motives of Market Mavens' Initiation of Information Diffusion'. 21(2):109-22.

Wang, Chen-ya, and Anna S. Mattila. 2010. 'A Grounded Theory Model of Service Providers' Stress, Emotion, and Coping during Intercultural Service Encounters'. Managing Service Quality: An International Journal.

Wang, Xuequn, and Zilong Liu. 2019. 'Online Engagement in Social Media: A Cross-Cultural Comparison'. Computers in Human Behavior 97:137-50.

Weiermair, Klaus. 2000. 'Tourists' Perceptions towards and Satisfaction with Service Quality in the Cross-cultural Service Encounter: Implications for Hospitality and Tourism Management'. 10(6):397-409.

Wu, Mao-Ying, and Philip L. Pearce. 2014. 'Appraising Netnography: Towards Insights about New Markets in the Digital Tourist Era'. Current Issues in Tourism 17(5):463-474.

Xiang, Zheng, and Ulrike Gretzel. 2010. 'Role of Social Media in Online Travel Information Search'. Tourism Management 31(2):179-88.

Xu, X., Wang, X., Li, Y., \& Haghighi, M. (2017). Business intelligence in online customer textual reviews: Understanding consumer perceptions and influential factors. International Journal of Information Management, 37(6), 673-683. 
Zeithaml, Valarie A., Leonard L. Berry, and A. Parasuraman. 1993. 'The Nature and Determinants of Customer Expectations of Service'. 21(1):1-12.

Zhang, Jingyun, Sharon E. Beatty, and Gianfranco Walsh. 2008. 'Review and Future Directions of Cross-Cultural Consumer Services Research'. Journal of Business Research 61(3):211-24.

Zhou, Tao. 2011. 'Understanding Online Community User Participation: A Social Influence Perspective'. 21(1):67-81.

Zhu, Feng, and Xiaoquan Zhang. 2010. 'Impact of Online Consumer Reviews on Sales: The Moderating Role of Product and Consumer Characteristics'. 74(2):133-48.

\section{Appendix A}

\begin{tabular}{|c|c|}
\hline Quotes - American Visitors & Codes \\
\hline $\begin{array}{l}\text { "Service was slow tho [1] or maybe im from new york } \\
\text { and not used to their pace [2]...def recommend another } \\
\text { pot of tea [3] if both travelers like tea as } 1 \text { pot that came } \\
\text { with it was not enough"[4]. }\end{array}$ & $\begin{array}{l}\text { [1] Staff attentiveness } \\
\text { [2] Comparisons to } \\
\text { experiences in America/ } \\
\text { England } \\
\text { [3] To influence others } \\
\text { [4] F+B Portion size }\end{array}$ \\
\hline $\begin{array}{l}\text { "There is a very expensive [5](not very good food [6] or } \\
\text { service [1]) restaurant..." }\end{array}$ & $\begin{array}{l}\text { [5] F+B Pricing } \\
\text { [6] F+B Quality } \\
\text { [1] Staff attentiveness }\end{array}$ \\
\hline $\begin{array}{l}\text { "...Great service [1], adored meeting toby, the executive } \\
\text { chef and part owner!! [7] You'll enjoy meeting him! !! } \\
\text { Highly recommend grabbing lunch or brunch here } \\
{[3] ! ! ! . . . "}\end{array}$ & $\begin{array}{l}\text { [1] Staff attentiveness } \\
\text { [7] Meeting the owners } \\
\text { [3] To influence others }\end{array}$ \\
\hline
\end{tabular}


"...the price point was low [5]( compared w/ other places [2]) and overall reviews were not too bad [8]...I finished my pot of tea( was 21/2 cups) [4] and when I asked for another they forgot about it and I had to reask for it. It was 10 minutes later that I reasked [1] They were busy, we could see them, but.. to just bring me another pot of tea? ... I was dissapointed because I didn't want to continue to eat w/ out a drink, so my hot scones got cold. The desserts were good and the sandwiches were not. very bland. [6] I don't know if all British tea sandwiches are like that because I have only had Tea in America." [2] [AML]

"Not one employee in site [1] and if you did see one they were on their phone!" [1].
[5] F+B Pricing

[2] Comparisons to experiences in America/ England

[8] Comparisons to other visitor experiences, based off reviews [4] F+B Portion size [1] Staff attentiveness [6] F+B Quality

[1] Staff attentiveness

\begin{tabular}{|l|l}
\hline Quotes - British Visitors & C \\
\hline
\end{tabular}

“... I insisted that although Strawberry Fields' lyrics were at the British Library, there were nine other Beatles lyrics here at the British Museum. The attendant screwed his face up like I was a martian. Then his female co worker chipped in 'We did have them on display, but they're not on display at the moment.' [9] She then told me that I sounded like I was from Liverpool - I confirmed that I was and she then said 'Well you've got a Beatles Museum in Liverpool why don't you go there?' [9]... Sad really - it all could have been better - and their assumption that the public are idiots / always wrong is an unfortunate one." [10]

"...It really did seem like it was an absolute imposition for the staff to tear themselves from chatting about their inane lives [1] than was to rip $£ 30$ from our hands... Best part about the British Museum is the architecture and permanent exhibits. It's lovely that general admission is free but if you taking money from guests then don't be so rude about it." [9]

\section{Codes}

[9] Friendliness

[10] Staff skills and training
[1] Staff attentiveness [9] Friendliness 
"...The inside is as beautiful as the outside of the building and this is without a doubt a popular attraction [11]... After locating the ticket office I enquired about all of the Egyptian exhibits. The woman was extremely rude and printed off two tickets with the response "£33". Nothing else verbally said albeit the non-verbal I interpreted as "pay and leave"...[9] The woman at the desk was too disinterested to offer us an audio guide as well as not mention the other Egyptian exhibits housed at the museum. [1] The service skills that woman demonstrated were poor and we ultimately missed out due to her lack of service skills [10]. On entrance we meet a very friendly woman from Toronto who allowed us to touch Egyptian amulets; [9]it was surprisingly emotional and I had goosebumps! The woman was extremely knowledgeable and did not mind answering all of our questions [12]... Cameras were not allowed but do bring comfortable shoes!...The tea was ok and the Victoria Sponge was dry and poor quality. The person who delivered our cake and tea could not even muster up a smile [9]. A tea cup of coffee, a pot of tea and 2 cakes were £16. [5] My advice would be to save that money for the exhibit! [3] At least the blonde hair woman who took our order and gave us the bill could smile and be polite ... a glimmer of hope!" [9]

Table A1: Coding table (note: quotes have been left in their original form)

\section{Appendix B}

The interview protocol is below. As the process was semi-structured each participant had various sub-questions. Therefore, we have only provided the five main questions here.

1. Tell me about your cultural background.

2. Describe your service expectations of the British Museum.

3. What level of interaction do you expect with British Museum staff members?

4. Are your service expectations the same when abroad, are you more forgiving of bad service?

5. What would motivate you to write a TripAdvisor review about a British Museum experience? 